\title{
Genetic Marker Analysis of a Global Collection of Isolates of Citrus tristeza virus: Characterization and Distribution of CTV Genotypes and Association with Symptoms
}

\author{
Mark E. Hilf, Vessela A. Mavrodieva, and Stephen M. Garnsey
}

First author: USDA-ARS-USHRL, 2001 S. Rock Rd., Fort Pierce, FL 34945; second author: Department of Plant Pathology, North Carolina State University, Raleigh 27695; and third author: USDA-ARS-USHRL, 2120 Camden Road, Orlando, FL, 32802 (Retired).

Current address of S. M. Garnsey: Citrus Research and Education Center, University of Florida, Lake Alfred 33850.

Accepted for publication 12 April 2005.

\begin{abstract}
Hilf, M. E., Mavrodieva, V. A., and Garnsey, S. M. 2005. Genetic marker analysis of a global collection of isolates of Citrus tristeza virus: Characterization and distribution of CTV genotypes and association with symptoms. Phytopathology 95:909-917.

Genetic markers amplified from three noncontiguous regions by sequence specific primers designed from the partial or complete genome sequences of Citrus tristeza virus (CTV) isolates T3, T30, T36, and VT were used to assess genetic relatedness of 372 isolates in an international collection. Eighty-five isolates were judged similar to the T3 isolate, 81 to T30, 11 to T36, and 89 to VT. Fifty-one isolates were mixed infections by

two or more identifiable viral genotypes, and 55 isolates could not be assigned unequivocally to a group defined by marker patterns. Maximum parsimony analysis of aligned marker sequences supported the grouping of isolates on the basis of marker patterns only. Specific disease symptoms induced in select citrus host plants were shared across molecular groups, although symptoms were least severe among isolates grouped by markers with the T30 isolate and were most severe among isolates grouped by markers with the T3 isolate. Isolates assigned the same genotype showed variable symptoms and symptom severity. A classification strategy for CTV isolates is proposed that combines genetic marker patterns and nucleotide sequence data.
\end{abstract}

Citrus tristeza virus (CTV) is a species of the Closterovirus genus of RNA plant viruses. CTV virions have a flexous filamentous morphology and a genome of single-stranded, positive-sense RNA. The virus has a host range restricted to plants in the family Rutaceae, including economically important members of the genus Citrus such as sweet orange and grapefruit. Historically, CTV has been a destructive pathogen in many of the world's citrusproduction areas and currently still is of concern from either a disease or regulatory perspective (23). A major disease caused by CTV is decline, a virus-induced graft incompatibility that occurs with sweet orange (Citrus sinensis (L.) Osb.) and other scions grafted onto sour orange rootstock ( $C$. aurantium $\mathrm{L}$.). This incompatibility can cause a rapid or gradual decline in the productivity of the tree, often resulting in death. Another destructive CTV syndrome is stem pitting, which debilitates the tree and reduces fruit size and production. Stem pitting has impacted grapefruit production in Australia (3) and South Africa (4) and also causes losses in sweet orange (19).

CTV was initially identified by disease symptoms that developed in the field and on graft-inoculated citrus indicator plants. Variability in symptoms was used to differentiate isolates or strains, two terms that are used interchangeably in the literature of CTV. Mild isolates cause only mild or no symptoms in sensitive citrus indicator hosts and usually result in no economic loss. Se-

Corresponding author: M. E. Hilf; E-mail address: MHilf@ushrl.ars.usda.gov

Mention of a trade name, proprietary product, or specific equipment does not constitute a guarantee or warranty by the U.S. Department of Agriculture and does not imply approval to the exclusion of other products that may also be suitable.

DOI: 10.1094/PHYTO-95-0909

This article is in the public domain and not copyrightable. It may be freely reprinted with customary crediting of the source. The American Phytopathological Society, 2005 vere isolates can cause decline, stem pitting, or both and may vary in intensity (7).

Polyclonal and monoclonal antibodies have been used for detection of CTV $(6,8,9,21,30,31)$. Certain monoclonal antibodies can discriminate between severe and mild CTV isolates (22). Recently, tests have been devised to predict symptom phenotypes of uncharacterized CTV isolates using serological or molecular genetic characters thought to be associated with specific disease phenotypes $(2,20,21)$.

The genomic sequences of seven isolates of CTV are known: T30, a mild isolate from Florida (1); T36, a decline isolate from Florida (14); VT, a decline isolate from Israel (17); SY568, a decline and sweet orange stem-pitting isolate from California (33); T385, a mild isolate from Spain (32); NUaga, an isolate from Japan (27); and Qaha, an isolate from Egypt (GenBank Accession No. AY340974). The genomes of these isolates vary slightly in size $(19,226$ to $19,302 \mathrm{nt})$ but the arrangement of the 12 open reading frames (ORFs) is similar. The $5^{\prime}$ proximal open reading frame (ORF 1) is translated from the genomic RNA to produce a $349-\mathrm{kDa}$ polyprotein (replicase). A translational frameshift in ORF 1 produces a larger protein with a RNA-dependent-RNApolymerase domain (14). The 10 smaller ORFS are expressed by translation from 3' co-terminal subgenomic RNAs (13).

Nucleotide sequence analyses showed that the degree and pattern of sequence divergence varied among isolates. The genomes of CTV isolates are conserved in the $3^{\prime}$ proximal $8 \mathrm{~kb}$, with a nucleotide sequence identity of $\geq 90 \%$ for the ORFs expressed from subgenomic RNAs. In pairwise comparisons, the 5' terminal $11 \mathrm{~kb}$ (ORF1) of VT, SY568, T30, T385, and NUaga all have nucleotide sequence identities similar to that of the $3^{\prime} 8 \mathrm{~kb}$. In contrast, pairwise comparisons of these isolates and T36 showed much greater divergence in the $5^{\prime}$ proximal $11 \mathrm{~kb}$ of the genome with only $40 \%$ nt sequence identity in the 5 ' nontranslated regions $(1,15,17,27,32)$. 
Polymerase chain reaction (PCR)-based methods and sequence specific primers designed from known CTV sequences were used to detect genetically similar isolates by amplification of similarsized DNA sequences (markers) from near the $5^{\prime}$ terminus of the genomic RNA or from multiple sites within ORF $1(2,10,12)$. Lopéz et al. (15) identified three sequence groups (I, II, and III) represented by isolates T36, VT, and T385, respectively. Using hybridization and PCR results, Hilf et al. $(10,12)$ recognized two large groups represented by isolates VT and T36. Within the VT group, three specific "genotypes" represented by the isolates VT, T30, and T3 were recognized. A study that applied genotype specific primers to a small sample of CTV isolates from domestic and international sources identified isolates with marker patterns similar to the type isolates, but also found isolates that yielded no sequence specific markers (10).

Molecular genetic data has provided a new measure of differences between CTV isolates but not a clarification of which differences (biological or genetic) should take precedence in defining relatedness. Studies by Niblett et al. (20) suggested that single nucleotide polymorphisms (SNPs) in the highly conserved viral capsid protein gene were sufficient to predict symptoms and to differentiate strains simultaneously. However, correlation between these SNPs and symptom phenotype was not rigorously tested, and designation of strain status based on SNPs in the capsid protein gene does not consider sequence divergence in other regions of the genome.

Assuming that biological phenotype and molecular genotype were of equal importance in constructing a classification strategy for CTV isolates, we expanded our earlier marker analysis to 372 isolates of CTV that had been gathered from 30 citrus-growing regions into a single collection (5). We also examined symptom data for 131 of these isolates with the following goals set for this study: (i) determine the extent of CTV genetic variability as measured by the marker system; (ii) examine symptom phenotype diversity and determine if specific symptom phenotypes might be associated with specific CTV genotypes; and (iii) design a simple classification scheme for CTV isolates.

\section{MATERIALS AND METHODS}

Virus propagation and symptom assessment. CTV isolates not endemic to citrus-production areas of the United States are maintained in planta as part of a collection of exotic citrus pathogens maintained at the USDA Beltsville Agricultural Research Center (BARC) in Beltsville, MD (5). Isolates in the collection were propagated primarily in sweet orange, and biological characteristics of isolates described in this study were determined according to a standardized protocol (7). Grapefruit seedlings (Citrus paradisi Macf. cv. Duncan) were used to evaluate the potential of isolates to induce stem pitting in grapefruit (GSP). Seedlings of cv. Madam Vinous sweet orange were used to evaluate the potential of isolates to induce stem pitting in sweet orange (OSP). Seedlings of sour orange were used to evaluate the development of chlorosis termed seedling yellows (SO-SY). Sweet orange plants grafted on sour orange rootstock $(\mathrm{S} / \mathrm{S})$ were used as indicators for the decline syndrome induced by CTV in fieldgrown mature orange, mandarin, and grapefruit trees grafted on sour orange rootstocks. Stunting and chlorosis in the S/S plants (SC-S/S) was considered an indication of CTV-induced budunion phloem necrosis associated with decline.

Indicator plants were graft inoculated with tissue from infected source plants, pruned to force new growth, and incubated in an air cooled partially shaded greenhouse for symptom expression. Foliar symptoms were rated visually following periodic flushes of new growth. Stem pitting was evaluated by removing the bark of inoculated plants 12 months after inoculation. Symptoms were rated using a 0 to 3 scale in which 0 indicated an absence of visible symptoms, 1 indicated mild symptoms, 2 indicated moder- ately strong symptoms, and 3 indicated severe symptoms. The ratings were averaged for three plants of each indicator to give a consensus reading for the test. In most instances, evaluations were performed twice and the ratings shown are the average.

Viral immunocapture-reverse transcription-polymerase chain reaction amplification (IC-RT-PCR) of viral genetic markers. Marker analysis and the IC-RT-PCR procedure for marker amplification from CTV-infected citrus tissue were previously described $(10,12)$. Briefly, $0.5 \mathrm{~g}$ of fresh or the desiccated equivalent of peeled stem bark or whole leaf petioles was pulverized in buffer using a Kleco 4200 pulverizer (Garcia Manufacturing, Visalia, CA). Virions were immunocaptured from this extract using CTV polyclonal IgG attached to magnetic beads coated with goat anti-rabbit antibodies (Dynal, Lake Success, NY). Reverse transcription and the amplification of sequence specific CTV molecular markers were performed using 11 pairs of oligonucleotide primers as previously described (10). Sequence specific primers for the T36, T30, and VT genomes were derived from GenBank Accession Nos. AY170468, AF260651, and U56902, respectively, and primers for the T3K17 marker were designed from an unpublished sequence (M. E. Hilf, unpublished). CTV cDNA $(5 \mu \mathrm{l})$ was amplified in a $25-\mu \mathrm{l}$ reaction volume containing a $1 \times$ concentration of reaction buffer (Promega Corp., Madison, WI), $0.2 \mathrm{mM}$ dNTPs, $1.5 \mathrm{mM} \mathrm{MgCl} 2,0.2 \mu \mathrm{m}$ of each primer and $0.625 \mathrm{U}$ of $\mathrm{Taq}$ polymerase (Promega Corp). Amplification profiles were $94^{\circ} \mathrm{C}$ for $30 \mathrm{~s}, 56^{\circ} \mathrm{C}$ for $60 \mathrm{~s}$, and $72^{\circ} \mathrm{C}$ for $60 \mathrm{~s}$ for 30 cycles. Reactions were incubated an additional $10 \mathrm{~min}$ at $72^{\circ} \mathrm{C}$ prior to maintenance at $4^{\circ} \mathrm{C}$ until analysis. Reaction products were analyzed by electrophoresis in TAE buffer on $1.5 \%$ agarose gels containing ethidium bromide at $200 \mathrm{ng}$ per $\mathrm{ml}$.

Cloning and sequencing of CTV genetic markers. A subset of amplified genetic markers was cloned using standard molecular biology protocols. Sequencing of these cloned markers was performed using an ABI 3700 automated sequencer at the USHRL Genomics Facility, Fort Pierce, FL or at the University of Georgia Molecular Instrumentation Facility, Athens, GA. A minimum of three clones was sequenced for each marker amplified.

Analysis of marker sequences. The marker sequences were edited to remove vector and primer sequences, and pairwise alignments were performed with the LALIGN program at the Biology Workbench, San Diego Supercomputer Center, University of California, San Diego. Multiple alignments were performed using ClustalX (29), and Genedoc v. 2.6.002 was used to edit alignments and generate a consensus sequence for each marker. Neighbor-joining and maximum parsimony analyses of the alignments were conducted with $\boldsymbol{M E G A}$ version 2.1, Arizona State University, Tempe, AZ.

\section{RESULTS}

Genotype assessment of exotic CTV isolates based on a profile of amplified markers. Three hundred seventy-two isolates of CTV from an international collection were characterized by amplification of linked sequence specific genetic markers from the genomic positions indicated in Figure 1 using the primer pairs depicted in Table 1. Each isolate was analyzed twice, and a genotype was assigned to the isolate based on the similarity of this marker pattern to the marker profiles of the designated standard reference isolates VT, T3, T30, and T36 (Table 2). The CP marker was used as an internal positive control for the reverse transcription step, and was not used to assess the genotype of an isolate.

Assignment of a genotype was usually unambiguous since many isolates produced marker patterns identical to one or more reference isolates. Isolates B166, B12, B326, and B183 are examples of isolates readily assigned VT, T3, T30, and T36 genotypes, respectively (Table 3 ). However, not all markers associated with one of the standard genotypes were amplified from every isolate. 
Isolate B7 yielded the VTPOL and T30POL markers (Table 3), which are amplified from equivalent genomic positions (Table 1). The T30POL marker is unique to the T30 genotype, so amplification from B7 was interpreted to indicate the presence of the T30 genotype even in the absence of the T30K17 and T30-5' markers. Among the reference profiles, the VTPOL marker is amplified from the two standard genotypes T3 and VT, but since the T3K17 marker was not amplified (the differential marker between these two genotypes), the presence of a VT genotype was indicated even with the lack of amplification of the VTK17 and VT-5' markers. On the basis of these criteria, B7 was designated a mixed infection of a T30 and a VT genotype. Isolate B37 was designated a mixed infection of the T36 and T3 genotypes based on amplification of T3 markers and the T36POL marker. The association of the T36POL marker with only the T36 genotype supported the assignment of the T36 genotype, without amplification of either the T36K17 or the T36-5' markers (Table 3). The amplification of the T30K17 marker, in the absence of the definitive T30POL marker, was not sufficient evidence to assign a T30 genotype. Isolate B369 was not assigned a standard genotype since amplification of only the VT-5' marker, which is shared by the T3, T30, and VT isolates, precluded unambiguous genotype designation.

Incidence of the T3, T30, and VT genotypes in the collection was equivalent with 85 (23\%), 81 (22\%), and 89 (24\%) isolates assigned each genotype, respectively (Table 4). The T36 genotype was assigned to only $11(3 \%)$ of the accessions. Fifty-one accessions $(14 \%)$ were identified as a mixed infection of two or more genotypes. The most common mix of genotypes was T30 + VT, with 23 occurrences. Two isolates, one from Israel and one from Trinidad, contained three CTV genotypes. Fifty-five (15\%) of the CTV accessions could not be assigned a standard genotype, either because they yielded no specific markers or they did not yield a marker profile consistent with a standard genotype.

Regional variability of CTV genotypes. The incidence of genotypes among CTV accessions from the different regions was variable (Table 4). Of the 15 isolates from India, 13 were identified as VT genotypes as were 16 of the 19 accessions from Israel. All 11 isolates from Cuba had a T30 genotype as did 17 of the 24 accessions from Spain. Of 18 isolates from Brazil, 13 had T3 genotypes, as did six of eight isolates from the Philippines, and four of six isolates from Indonesia. In contrast, all four standard genotypes and two different mixtures of genotypes were represented in the accessions from China, as were seven accessions that could not be assigned a standard genotype. Nineteen of the 25 isolates from Australia could not be assigned a standard genotype, suggesting a high incidence of genotypes that are genetically distinct from the standards. However, 14 of these 19 isolates are aphid-transmitted subisolates from only two sources, suggesting that the proportion of genetically distinct Australian isolates might be less than indicated (S. M. Garnsey, personal communication). The limited number of accessions from some countries (e.g., Malaysia, Thailand, and Turkey) prevented a useful assessment of genotype variability for these regions.

Association of genotype and symptoms. Bio-indexing revealed a high level of variability in the degree and pattern of symptom expression with 13 symptom profiles observed among 131 isolates. During evaluation of stem-pitting symptoms in in- oculated grapefruit seedlings, in contrast to discrete pits associated with GSP, some isolates caused a porous wood pitting with stunting and thickened stem bark. This condition was scored as a severe form of pitting and given a "3" rating. With other isolates in grapefruit seedlings, thickened bark occurred with stunting and severe chlorosis, but no wood pitting. In these instances, bristles extended out from the wood surface when bark was removed, in contrast to pits in the wood. This was regarded as a seedling yellows response in grapefruit and not scored as stem pitting.

Thirteen symptom profiles with differing combinations of the GSP, OSP, SY, and SC-S/S syndromes were detected with varying frequency and are summarized in Table 5. Profile 1 (symptoms in all index hosts) was most common and occurred with 27 isolates associated with the T3 and VT genotypes. Profile 13 (no symptoms) occurred with 16 isolates, 12 of which were the T30 genotype. GSP occurred independently in Profiles 3, 5, 9, and 12 with 31 isolates, and in conjunction with OSP with 35 isolates (Profiles $1,6,8$, and 11). OSP occurred independently of GSP for 13 isolates (Profile 2).

SC-S/S was the most common symptom (Profiles 1-7), produced by 98 isolates. SC-S/S occurred in conjunction with the SO-SY reaction for 72 isolates (Profiles 1-4) and was independent of SO-SY for 26 isolates (Profiles 5-7). SO-SY occurred independent of SC-S/S for 4 isolates (Profiles 8-10).

Table 6 summarizes the data on association of genotype with symptoms presented in Table 5. The highest incidence of symptoms and the most severe symptoms were associated with the T3 genotype. Thirty-one of 48 isolates (64\%) which expressed OSP had the T3 genotype. In contrast, no OSP occurred with the T30 genotype and there was only one occurrence with the T36 genotype. GSP occurred with $44 \%$ of the T30 genotype isolates, al-

TABLE 1. Sequences of marker primers and genomic positions of markers

\begin{tabular}{|c|c|c|c|}
\hline Marker & Size & $\left(5^{\prime} \rightarrow 3^{\prime}\right)$ & Marker position \\
\hline T36CP & 671 & $\begin{array}{l}\text { (+) atggacgacgaaacaaagaaattg } \\
(-) \text { tcaacgtgtgttgaatttccca }\end{array}$ & $16,152-16,823$ \\
\hline T36-5' & 500 & $\begin{array}{l}\text { (+) aatttcacaaattcaacctg } \\
(-) \text { ctttgcetgacggagggacc }\end{array}$ & $1-500$ \\
\hline T36K 17 & 409 & $\begin{array}{l}\text { (+) gttttctcgtttgaagcggaaa } \\
(-) \text { caacacatcaaaaatagctagt }\end{array}$ & $4,865-5,273$ \\
\hline T36POL & 714 & $\begin{array}{l}\text { (+) tgacgctaacgacgataacg } \\
(-) \text { accetcggcttgttttcttatg }\end{array}$ & $10,791-11,508$ \\
\hline T30-5' & 594 & $\begin{array}{l}(+) \text { cgattcaaattcacccgtatc } \\
(-) \text { tagtttcgcaacacgcetgcg }\end{array}$ & $6-600$ \\
\hline T30K17 & 409 & $\begin{array}{l}\text { (+) gttgtcgcgcctaaagttcggca } \\
(-) \text { tatgacatcaaaaatagctgaa }\end{array}$ & $4,848-5,256$ \\
\hline T30POL & 696 & $\begin{array}{l}\text { (+) gatgctagcgatggtcaaat } \\
(-) \text { ctcagctcgctttctcacat }\end{array}$ & $10,772-11,467$ \\
\hline VT-5' & 492 & $\begin{array}{l}\text { (+) aatttctcaaattcacccgtac } \\
(-) \text { cttcgccttggcaatggactt }\end{array}$ & $1-492$ \\
\hline VTK17 & 409 & $\begin{array}{l}\text { (+) gttgtcgcgctttaagttcggta } \\
(-) \text { tacgacgttaaaaatggctgaa }\end{array}$ & $4,824-5,232$ \\
\hline VTPOL & 695 & $\begin{array}{l}\text { (+) gacgctagcgatggtcaagc } \\
(-) \text { ctcggctcgctttcttacgt }\end{array}$ & $10,745-11,440$ \\
\hline T3K17 & 409 & $\begin{array}{l}(+) \text { gttatcacgcctaaagtttggt } \\
(-) \text { catgacatcgaagatagccgaa }\end{array}$ & $4,871-5,279$ \\
\hline
\end{tabular}

a T36, T30, and VT primer sequences and marker positions are from GenBank Accession Nos. AY170468, AF260651, and U56902, respectively. Genomic position of T3 marker was derived from pairwise alignment with the T36 genomic sequence.

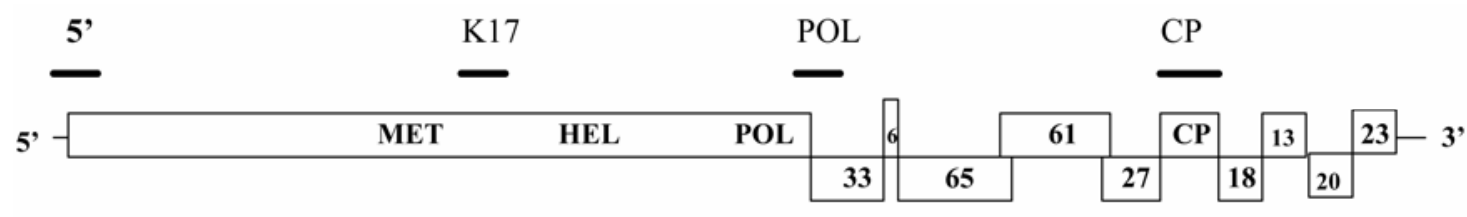

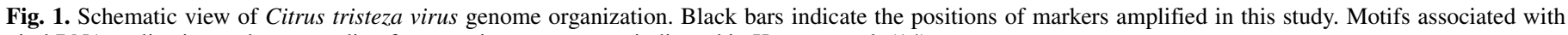
viral RNA replication and open reading frame assignments are as indicated in Karasev et al. (14). 
TABLE 2. Marker patterns of standard Citrus tristeza virus genotypes

\begin{tabular}{|c|c|c|c|c|c|c|c|c|c|c|c|c|}
\hline Region & Isolate & $\mathrm{CP}$ & T36-5' & T36K17 & T36POL & T30-5' & T30K17 & T30POL & VT-5' & VTK17 & VTPOL & $\mathrm{T} 3 \mathrm{~K} 17$ \\
\hline Florida & T36 & $1^{\mathrm{a}}$ & 1 & 1 & 1 & 0 & 0 & 0 & 0 & 0 & 0 & 0 \\
\hline Florida & T30 & 1 & 0 & 0 & 0 & 1 & 1 & 1 & 1 & 1 & 0 & 0 \\
\hline Florida & $\mathrm{T} 3$ & 1 & 0 & 0 & 0 & 0 & 0 & 0 & 1 & 0 & 1 & 1 \\
\hline Israel & VT & 1 & 0 & 0 & 0 & 0 & 1 & 0 & 1 & 1 & 1 & 0 \\
\hline
\end{tabular}

a 1 Indicates marker amplification and 0 indicates no amplification.

TABLE 3. Genotype determination of Citrus tristeza virus isolates based on marker patterns

\begin{tabular}{|c|c|c|c|c|c|c|c|c|c|c|c|c|c|}
\hline Region & Isolate & $\mathrm{CP}$ & T36-5' & $\mathrm{T} 36 \mathrm{~K} 17$ & T36POL & T30-5' & T30K17 & T30POL & VT-5' & VTK17 & VTPOL & T3K17 & Genotype \\
\hline India & B166 & $1^{\mathrm{a}}$ & 0 & 0 & 0 & 0 & 1 & 0 & 1 & 1 & 1 & 0 & VT \\
\hline Brazil & B12 & 1 & 0 & 0 & 0 & 0 & 0 & 0 & 1 & 0 & 1 & 1 & $\mathrm{~T} 3$ \\
\hline Dominican Republic & B326 & 1 & 0 & 0 & 0 & 1 & 1 & 1 & 1 & 0 & 0 & 0 & $\mathrm{~T} 30$ \\
\hline Costa Rica & B183 & 1 & 1 & 1 & 1 & 0 & 0 & 0 & 0 & 0 & 0 & 0 & T36 \\
\hline South Africa & B7 & 1 & 0 & 0 & 0 & 0 & 0 & 1 & 0 & 0 & 1 & 0 & $\mathrm{~T} 30+\mathrm{VT}$ \\
\hline Australia & B369 & 1 & 0 & 0 & 1 & 0 & 1 & 0 & 1 & 0 & 1 & 1 & Unknown \\
\hline Taiwan & B37 & 1 & 0 & 0 & 1 & 0 & 1 & 0 & 1 & 0 & 1 & 1 & $\mathrm{~T} 36+\mathrm{T} 3$ \\
\hline
\end{tabular}

a 1 Indicates marker amplification and 0 indicates no amplification.

TABLE 4. Summary of isolate genotypes determined by marker analysis

\begin{tabular}{|c|c|c|c|c|c|c|c|c|c|c|c|c|c|}
\hline Origin & $\begin{array}{c}\text { No. } \\
\text { isolates }\end{array}$ & $\mathrm{T} 3$ & $\mathrm{~T} 30$ & T36 & VT & $\mathrm{T} 3+\mathrm{T} 30$ & $\mathrm{~T} 36+\mathrm{VT}$ & $\mathrm{T} 30+\mathrm{VT}$ & $\mathrm{T} 3+\mathrm{T} 36$ & $\mathrm{~T} 36+\mathrm{T} 30$ & $\mathrm{~T} 3+\mathrm{T} 30+\mathrm{T} 36$ & $\mathrm{VT}+\mathrm{T} 30+\mathrm{T} 36$ & Unassigned \\
\hline Argentina & 8 & 5 & & & 3 & & & & & & & & \\
\hline Australia & 25 & & 3 & & 1 & 2 & & & & & & & 19 \\
\hline Belize & 6 & & 6 & & & & & & & & & & \\
\hline Bermuda & 2 & & & & 1 & & & 1 & & & & & \\
\hline Brazil & 18 & 13 & & & 3 & & & & & & & & 2 \\
\hline California & 28 & 4 & 12 & & 8 & 2 & & 1 & & & & & 1 \\
\hline China & 22 & 4 & 4 & 1 & 3 & 1 & & & 2 & & & & 7 \\
\hline Colombia & 22 & 11 & 2 & & 5 & 1 & & 2 & & & & & 1 \\
\hline Corsica & 3 & & & 2 & 1 & & & & & & & & \\
\hline Costa Rica & 8 & & 2 & 5 & & 1 & & & & & & & \\
\hline Cuba & 11 & & 11 & & & & & & & & & & \\
\hline Dom Rep ${ }^{a}$ & 29 & 7 & 7 & & & 3 & & 12 & & & & & \\
\hline Guatemala & 1 & & & 1 & & & & & & & & & \\
\hline Hawaii & 12 & 5 & & & 6 & & & & & & & & 1 \\
\hline India & 15 & & & & 13 & & & & & & & & 2 \\
\hline Indonesia & 6 & 4 & & & 1 & & & & & & & & 1 \\
\hline Israel & 19 & & & & 16 & & & 1 & & & 1 & & 1 \\
\hline Jamaica & 1 & & & & & & & & & & & & 1 \\
\hline Japan & 20 & 6 & 5 & & 2 & 1 & & & & & & & 6 \\
\hline Malaysia & 1 & 1 & & & & & & & & & & & \\
\hline Peru & 19 & 7 & 1 & & 6 & & 1 & 3 & & & & & 1 \\
\hline Phillipines & 8 & 6 & & & 1 & & & & & & & & 1 \\
\hline Puerto Rico & 10 & & 6 & & 3 & & & & & & & & 1 \\
\hline Reunion & 1 & & & & 1 & & & & & & & & \\
\hline South Africa & 14 & 3 & & & 9 & & & 1 & 1 & & & & \\
\hline Spain & 24 & & 17 & 1 & & 2 & & 1 & & 1 & & & 2 \\
\hline Taiwan & 26 & 7 & 2 & & 2 & 3 & & & 5 & & & & 7 \\
\hline Tanzania & 3 & & 1 & & 1 & & & & & & & & 1 \\
\hline Thailand & 2 & & & & 2 & & & & & & & & \\
\hline Trinidad & 4 & & 1 & 1 & & & & 1 & & & & 1 & \\
\hline Turkey & 1 & & & & 1 & & & & & & & & \\
\hline Venezuela & 3 & 2 & 1 & & & & & & & & & & \\
\hline Total & 372 & 85 & 81 & 11 & 89 & 16 & 1 & 23 & 8 & 1 & 1 & 1 & 55 \\
\hline
\end{tabular}

${ }^{\text {a }}$ Dom Rep $=$ Dominican Republic.

though this was a smaller percentage than that associated with the T3 $(67 \%)$ and VT (56\%) genotypes, and the average symptom severity was much greater for the T3 genotype compared with the T30 genotype.

SC-S/S occurred with $91,85,80$, and $46 \%$ of the T3, VT, T36, and T30 genotypes, respectively (Table 6). T3 genotypes produced more severe stunting compared with the T30 genotype. Stunting of sweet orange on sour orange rootstock occurred with SO-SY for 38 of 39 (T3) and 24 of 33 (VT) isolates, respectively (Table 5), but with the T30 genotype, only five of 18 isolates expressed SC-S/S concurrently with SO-SY.
Analysis of marker sequences. Sequences of cDNA clones of POL and K17 markers selected from symptomatically and geographically diverse isolates of each genotype (Table 7) were analyzed to determine if the groupings based on similar marker profiles represented natural delineations based on phylogenetic relatedness. Three to five clones of each marker were sequenced, and a consensus sequence for each marker was created from the alignment of sequences of individual clones. As indicated in Table 7, only the VTPOL marker from isolate B133 (T3 genotype) and only the T30K17 marker for B213 (T30 genotype) were cloned and sequenced. Only the T36POL 


\begin{tabular}{|c|c|c|c|c|c|c|c|c|c|}
\hline \multirow[b]{2}{*}{ Profile } & \multicolumn{4}{|c|}{ Symptoms ${ }^{\mathrm{a}}$} & \multicolumn{5}{|c|}{ Genotype } \\
\hline & SC-S/S & SO-SYc & $\mathrm{GSP}^{\mathrm{d}}$ & $\mathrm{OSP}^{\mathrm{e}}$ & $\mathrm{T} 3$ & VT & $\mathrm{T} 30$ & $\mathrm{~T} 36$ & Total \\
\hline 1 & + & + & + & + & 18 & 9 & 0 & 0 & 27 \\
\hline 2 & + & + & - & + & 8 & 5 & 0 & 0 & 13 \\
\hline 3 & + & + & + & - & 6 & 4 & 2 & 1 & 13 \\
\hline 4 & + & + & - & - & 6 & 6 & 3 & 4 & 19 \\
\hline 5 & + & - & + & - & 0 & 5 & 7 & 0 & 12 \\
\hline 6 & + & - & + & + & 1 & 2 & 0 & 1 & 4 \\
\hline 7 & + & - & - & - & 0 & 2 & 6 & 2 & 10 \\
\hline 8 & - & + & + & + & 1 & 0 & 0 & 0 & 1 \\
\hline 9 & - & + & + & - & 0 & 0 & 1 & 1 & 2 \\
\hline 10 & - & + & - & - & 0 & 0 & 1 & 0 & 1 \\
\hline 11 & - & - & + & + & 3 & 0 & 0 & 0 & 3 \\
\hline 12 & - & - & + & - & 0 & 2 & 7 & 1 & 10 \\
\hline 13 & - & - & - & - & 0 & 4 & 12 & 0 & 16 \\
\hline
\end{tabular}

a + or - Indicate symptoms expressed or not expressed, respectively, in indicator plants.

b Stunting and chlorosis of sweet orange on sour orange rootstock.

c Stunting and chlorosis of inoculated sour orange seedlings.

d Stem-pitting symptoms on inoculated grapefruit seedlings.

e Stem-pitting symptoms on inoculated sweet orange seedlings.

TABLE 6. Symptom incidence ${ }^{\mathrm{a}}$ and average symptom severity ${ }^{\mathrm{b}}$ associated with standard Citrus tristeza virus genotypes

\begin{tabular}{lrrll}
\hline Genotype & \multicolumn{1}{c}{ SC-S/S } & \multicolumn{1}{c}{ SO-SY $^{\mathrm{d}}$} & \multicolumn{1}{c}{ GSP $^{\mathrm{e}}$} & \multicolumn{1}{c}{ OSP $^{\mathrm{f}}$} \\
\hline T3 & $39 / 43(2.07)$ & $39 / 43(2.00)$ & $29 / 43(1.21)$ & $31 / 43(1.33)$ \\
VT & $33 / 39(1.61)$ & $24 / 39(1.10)$ & $22 / 39(0.96)$ & $16 / 39(0.64)$ \\
T36 & $8 / 10(0.65)$ & $6 / 10(0.62)$ & $4 / 10(0.45)$ & $1 / 10(0.05)$ \\
T30 & $18 / 39(0.55)$ & $7 / 39(0.15)$ & $17 / 39(0.36)$ & $0 / 39(0.00)$ \\
\hline
\end{tabular}

${ }^{a}$ Number of isolates showing indicated symptoms per number of isolates indexed.

${ }^{\text {b }}$ Symptom severity (in parentheses) was assessed by using a 1 to 3 scale in which $1=$ the least and $3=$ the most severe.

${ }^{c}$ Stunting and chlorosis of sweet orange on sour orange rootstock.

d Stunting and chlorosis of inoculated sour orange seedlings.

e Stem-pitting symptoms on inoculated grapefruit seedlings.

${ }^{f}$ Stem-pitting symptoms on inoculated sweet orange seedlings.

marker was sequenced for isolate B83 since no other T36 specific markers were amplified.

The pairwise identities for the consensus nucleotide sequences are presented in Tables 8 and 9. Pairwise identities of POL and K17 markers from isolates with T30 genotypes showed a range of identities from 97 to $99 \%$ for the POL markers and 98 to $100 \%$ for the K17 markers. Pairwise values for T30K17 and T30POL markers ( 89 to $93 \%$ ) were greater than those of the K17 and POL markers for T3 and VT genotypes ( 83 to $86 \%$ ). Ranges of 95 to $99 \%$ and 98 to $100 \%$ identity, respectively, were obtained for the K17 and POL marker sequences from comparisons between isolates with the T36 genotype. In contrast, pairwise identities for the T36K17 and T36POL markers obtained from comparisons with the other K17 and POL markers ranged from 66 to $69 \%$ and 85 to $87 \%$, respectively.

For designated VT genotypes, the sequences of the VTK17 markers showed high intragroup identities (96 to $99 \%$ ). In contrast, the sequences of VTPOL markers showed a broader range of intragroup pairwise identities. Values for sequences amplified from VT genotypes (89 to 99\%) were comparable with those amplified from T3 genotypes (91 to 100\%). With the current marker system, the T3 genotype is defined by amplification of the T3K17 marker. The nucleotide sequence identities of the T3K17 markers for B14, B211, B41, and B425 ranged from 95 to $98 \%$ when compared with one another, but unexpectedly, from only 85 to $87 \%$ when compared with $\mathrm{T} 3$, the type isolate for this group.

Neighbor-joining and maximum parsimony analyses were applied to sequences of the K17 and POL markers. Both methods produced consensus trees with equivalent topology (data not shown). The consensus trees obtained from maximum parsimony
TABLE 7. Markers cloned and sequenced for phylogenetic analysis

\begin{tabular}{|c|c|c|c|c|}
\hline Genotype & Isolate & Origin & Marker & $\begin{array}{c}\text { GenBank } \\
\text { Accession No. }\end{array}$ \\
\hline \multirow[t]{11}{*}{$\mathrm{T} 3$} & \multirow[t]{2}{*}{ B41 } & \multirow[t]{2}{*}{ Republic of China } & T3K17 & AY756283 \\
\hline & & & VTPOL & AY756284 \\
\hline & \multirow[t]{2}{*}{ B14 } & \multirow[t]{2}{*}{ Brazil } & T3K17 & AY756280 \\
\hline & & & VTPOL & AY756279 \\
\hline & \multirow[t]{2}{*}{ B211 } & \multirow[t]{2}{*}{ Republic of China } & T3K17 & AY756295 \\
\hline & & & VTPOL & AY756296 \\
\hline & \multirow[t]{2}{*}{$\mathrm{T} 3$} & \multirow[t]{2}{*}{ Florida (USA) } & T3K17 & AY756314 \\
\hline & & & VTPOL & AY756315 \\
\hline & B133 & Peru & VTPOL & AY756290 \\
\hline & \multirow[t]{2}{*}{ B425 } & \multirow[t]{2}{*}{ Dominican Republic } & T3K17 & AY756312 \\
\hline & & & VTPOL & AY756313 \\
\hline \multirow[t]{12}{*}{ VT } & \multirow[t]{2}{*}{ B1 } & \multirow[t]{2}{*}{ Reunion } & VTK17 & AY756278 \\
\hline & & & VTPOL & AY756277 \\
\hline & \multirow[t]{2}{*}{ B59 } & \multirow[t]{2}{*}{ South Africa } & VTK17 & AY756285 \\
\hline & & & VTPOL & AY756286 \\
\hline & \multirow[t]{2}{*}{ B152 } & \multirow[t]{2}{*}{ California (USA) } & VTK17 & AY756291 \\
\hline & & & VTPOL & AY756292 \\
\hline & \multirow{2}{*}{ B219 } & \multirow{2}{*}{ India } & VTK17 & AY756298 \\
\hline & & & VTPOL & AY756299 \\
\hline & \multirow[t]{2}{*}{ B79 } & \multirow[t]{2}{*}{ South Africa } & VTK17 & AY756287 \\
\hline & & & VTPOL & AY756288 \\
\hline & \multirow[t]{2}{*}{ B370 } & \multirow[t]{2}{*}{ Australia } & VTK17 & AY756310 \\
\hline & & & VTPOL & AY756311 \\
\hline \multirow[t]{7}{*}{ T30 } & B213 & South Korea & T30K17 & AY756297 \\
\hline & \multirow[t]{2}{*}{ B271 } & \multirow[t]{2}{*}{ Costa Rica } & T30K17 & AY756302 \\
\hline & & & T30POL & AY756303 \\
\hline & B348 & California (USA) & T30K17 & AY756304 \\
\hline & & & T30POL & AY756305 \\
\hline & B270-1 & People's Republic of China & T30K17 & AY756300 \\
\hline & & & T30POL & AY756301 \\
\hline T36 & B33 & Spain & T36K17 & AY756282 \\
\hline & & & T36POL & AY756281 \\
\hline & B183 & Costa Rica & T36K17 & AY756293 \\
\hline & & & T36POL & AY756294 \\
\hline & B358 & Corsica & T36K17 & AY756306 \\
\hline & & & T36POL & AY756307 \\
\hline & B359 & Corsica & T36K17 & AY756308 \\
\hline & & & T36POL & AY756309 \\
\hline & B83 & People's Republic of China & T36POL & AY756289 \\
\hline
\end{tabular}

analysis for sequences for the K17 and POL markers are discussed here, with trees ( $70 \%$ or greater boot-strap support) presented as unrooted, rectangular cladograms. The sequences of the K17 markers from the five T36 genotype isolates clustered together and were distinct from the other genotypes (Fig. 2A), supporting the grouping based on marker patterns. Interestingly, the $\mathrm{K} 17$ sequence from isolate $\mathrm{B} 33$ was placed on a branch sepa- 
rate from other $\mathrm{T} 36 \mathrm{~K} 17$ sequences. The $\mathrm{K} 17$ sequences for isolates grouped with T3, VT, or T30 were part of a larger cluster separated from the T36 group at node "A" (Fig. 2A). Within this larger cluster, sequences for the T30 genotype isolates (B213, B270-1, B271, T30, and B348) formed a cluster distinct from the VT and T3 K17 sequences. VTK17 sequences (VT, B152, B370, B1, B59, and B219) and T3K17 sequences (B14, B211, B425, and B41) also formed distinct clusters (Fig. 2A), again in apparent support of groupings based on marker patterns. Unexpectedly, the T3K17 sequence for T3, the type isolate for the T3 genotype, occupied a separate branch distinct from the other T3 isolates. Apparently, the T3K17 primers amplified sequences closely related to each other (B14, B211, B425, and B41), but distinct from T3.

Topology of the maximum parsimony consensus tree for the POL marker sequences was similar to that for the K17 marker sequences in that the VT, T30, and T3 sequences were part of a larger cluster separated from the T36POL sequences (Fig. 2B, node "B"). Within this larger cluster, T30POL sequences branched separately from VTPOL sequences, in agreement with groupings based on marker profiles. However, the VTPOL marker sequences did not cluster in support of groupings based on T3 and VT marker profiles. The T3 genotype isolates B425 and B133 formed a separate cluster, and the B14 and B211 VTPOL sequences each branched separately from other T3 VTPOL sequences. The VTPOL sequences of T3 and B41 clustered with VTPOL sequences from isolates with a VT genotype (B370, B1, B59, and B219), whereas VTPOL sequences for isolates VT, B152, and B79 (VT genotype) formed a separate cluster.

Within the T36 cluster, isolate B83 branched separately (Fig. 2B) and Table 9 shows that B83 shared only 94 to $95 \%$ sequence identity with the other isolates in the T36 group. The POL sequence for isolate B33 clustered with other T36 genotype isolates (B183, T36, B359, and B358), whereas the K17 sequence for B33 branched separately (Fig. 2A).

TABLE 8. Pairwise nucleotide sequence identities of K17 markers

\begin{tabular}{|c|c|c|c|c|c|c|c|c|c|c|c|c|c|c|c|c|c|c|c|c|c|c|}
\hline & \multicolumn{7}{|c|}{ VT Genotype } & \multicolumn{5}{|c|}{ T3 Genotype } & \multicolumn{5}{|c|}{ T30 Genotype } & \multicolumn{5}{|c|}{ T36 Genotype } \\
\hline & VT & B1 & B152 & B219 & B370 & B59 & B79 & T3 & B14 & B211 & B41 & B425 & T30 & B213 & B271 & B348 & B270-1 & T36 & B33 & B183 & B358 & B359 \\
\hline VT & & 96 & 97 & 96 & 97 & 96 & 97 & 87 & 87 & 88 & 87 & 88 & 89 & 90 & 89 & 89 & 90 & 67 & 67 & 66 & 67 & 67 \\
\hline B1 & & & 97 & 97 & 97 & 97 & 97 & 89 & 88 & 89 & 87 & 89 & 90 & 91 & 90 & 90 & 91 & 67 & 68 & 68 & 67 & 67 \\
\hline B152 & & & & 97 & 97 & 98 & 99 & 88 & 89 & 90 & 88 & 90 & 90 & 91 & 90 & 90 & 91 & 68 & 68 & 68 & 68 & 68 \\
\hline B219 & & & & & 97 & 98 & 97 & 90 & 88 & 89 & 88 & 90 & 92 & 93 & 92 & 92 & 93 & 68 & 68 & 68 & 68 & 68 \\
\hline B370 & & & & & & 98 & 99 & 88 & 89 & 90 & 88 & 90 & 90 & 91 & 90 & 90 & 91 & 68 & 68 & 68 & 68 & 68 \\
\hline B59 & & & & & & & 98 & 89 & 89 & 89 & 88 & 89 & 91 & 92 & 91 & 91 & 92 & 67 & 67 & 67 & 67 & 67 \\
\hline B79 & & & & & & & & 89 & 89 & 90 & 89 & 90 & 91 & 91 & 90 & 91 & 91 & 68 & 68 & 68 & 68 & 68 \\
\hline $\mathrm{T} 3$ & & & & & & & & & 85 & 87 & 85 & 85 & 89 & 90 & 89 & 89 & 90 & 66 & 66 & 66 & 66 & 66 \\
\hline B14 & & & & & & & & & & 98 & 95 & 95 & 90 & 89 & 90 & 90 & 89 & 68 & 68 & 68 & 68 & 68 \\
\hline B211 & & & & & & & & & & & 96 & 95 & 90 & 90 & 90 & 90 & 90 & 68 & 68 & 68 & 68 & 68 \\
\hline B41 & & & & & & & & & & & & 96 & 89 & 89 & 89 & 89 & 89 & 69 & 69 & 69 & 69 & 69 \\
\hline B425 & & & & & & & & & & & & & 90 & 90 & 90 & 90 & 90 & 69 & 69 & 69 & 69 & 69 \\
\hline T30 & & & & & & & & & & & & & & 98 & 98 & 100 & 98 & 68 & 68 & 68 & 68 & 68 \\
\hline B213 & & & & & & & & & & & & & & & 98 & 98 & 100 & 68 & 68 & 68 & 68 & 68 \\
\hline B271 & & & & & & & & & & & & & & & & 99 & 98 & 68 & 68 & 68 & 68 & 68 \\
\hline B348 & & & & & & & & & & & & & & & & & 98 & 68 & 68 & 68 & 68 & 68 \\
\hline B270-1 & & & & & & & & & & & & & & & & & & 68 & 68 & 68 & 68 & 68 \\
\hline T36 & & & & & & & & & & & & & & & & & & & 99 & 99 & 100 & 100 \\
\hline B33 & & & & & & & & & & & & & & & & & & & & 98 & 99 & 99 \\
\hline B183 & & & & & & & & & & & & & & & & & & & & & 99 & 99 \\
\hline B358 & & & & & & & & & & & & & & & & & & & & & & 100 \\
\hline B359 & & & & & & & & & & & & & & & & & & & & & & \\
\hline
\end{tabular}

TABLE 9. Pairwise nucleotide sequence identities of POL markers

\begin{tabular}{|c|c|c|c|c|c|c|c|c|c|c|c|c|c|c|c|c|c|c|c|c|c|c|c|}
\hline & \multicolumn{7}{|c|}{ VT Genotype } & \multicolumn{6}{|c|}{ T3 Genotype } & \multicolumn{4}{|c|}{ T30 Genotype } & \multicolumn{6}{|c|}{ T36 Genotype } \\
\hline & VT & B1 & B152 & B219 & B370 & B59 & B79 & T3 & B133 & B14 & B211 & B41 & B425 & T30 & B271 & B348 & B270-1 & T36 & B33 & B83 & B183 & B358 & B359 \\
\hline VT & & 90 & 97 & 89 & 92 & 89 & 96 & 90 & 95 & 92 & 95 & 89 & 95 & 83 & 83 & 84 & 84 & 83 & 84 & 83 & 84 & 83 & 84 \\
\hline B1 & & & 92 & 96 & 97 & 96 & 91 & 96 & 92 & 92 & 91 & 96 & 92 & 84 & 84 & 84 & 84 & 83 & 84 & 83 & 84 & 83 & 83 \\
\hline B152 & & & & 91 & 94 & 91 & 99 & 91 & 97 & 95 & 97 & 91 & 97 & 84 & 84 & 85 & 85 & 84 & 85 & 83 & 85 & 85 & 85 \\
\hline B219 & & & & & 94 & 97 & 90 & 97 & 90 & 90 & 91 & 97 & 90 & 84 & 84 & 83 & 83 & 82 & 83 & 82 & 83 & 82 & 82 \\
\hline B370 & & & & & & 95 & 94 & 94 & 94 & 94 & 94 & 94 & 94 & 85 & 85 & 85 & 85 & 83 & 84 & 83 & 84 & 83 & 84 \\
\hline B59 & & & & & & & 90 & 96 & 90 & 90 & 90 & 98 & 90 & 83 & 83 & 83 & 83 & 82 & 83 & 82 & 83 & 82 & 83 \\
\hline B79 & & & & & & & & 91 & 96 & 94 & 97 & 91 & 96 & 84 & 84 & 85 & 85 & 84 & 85 & 83 & 85 & 85 & 85 \\
\hline $\mathrm{T} 3$ & & & & & & & & & 91 & 91 & 91 & 96 & 91 & 84 & 84 & 84 & 84 & 83 & 83 & 83 & 83 & 83 & 83 \\
\hline B133 & & & & & & & & & & 96 & 98 & 91 & 100 & 86 & 86 & 86 & 86 & 85 & 85 & 84 & 85 & 85 & 85 \\
\hline B14 & & & & & & & & & & & 96 & 90 & 96 & 85 & 85 & 85 & 85 & 83 & 84 & 82 & 84 & 83 & 83 \\
\hline B211 & & & & & & & & & & & & 91 & 98 & 85 & 85 & 86 & 86 & 81 & 84 & 83 & 84 & 83 & 84 \\
\hline B41 & & & & & & & & & & & & & 91 & 83 & 83 & 83 & 83 & 82 & 83 & 82 & 83 & 83 & 83 \\
\hline B425 & & & & & & & & & & & & & & 86 & 86 & 86 & 86 & 85 & 85 & 84 & 85 & 85 & 85 \\
\hline T30 & & & & & & & & & & & & & & & 99 & 99 & 97 & 81 & 82 & 81 & 82 & 81 & 82 \\
\hline B271 & & & & & & & & & & & & & & & & 99 & 97 & 81 & 82 & 81 & 82 & 81 & 82 \\
\hline B348 & & & & & & & & & & & & & & & & & 97 & 81 & 82 & 81 & 82 & 81 & 82 \\
\hline B270-1 & & & & & & & & & & & & & & & & & & 81 & 82 & 82 & 82 & 81 & 82 \\
\hline T36 & & & & & & & & & & & & & & & & & & & 99 & 95 & 99 & 98 & 99 \\
\hline B33 & & & & & & & & & & & & & & & & & & & & 95 & 99 & 98 & 99 \\
\hline B83 & & & & & & & & & & & & & & & & & & & & & 95 & 94 & 95 \\
\hline B183 & & & & & & & & & & & & & & & & & & & & & & 98 & 99 \\
\hline B358 & & & & & & & & & & & & & & & & & & & & & & & 98 \\
\hline B359 & & & & & & & & & & & & & & & & & & & & & & & \\
\hline
\end{tabular}


Classification strategy for CTV. On the basis of marker and sequence data, we propose a classification scheme for CTV that recognizes two major groups, the VT and T36 groups, as defined by major branch points in the maximum parsimony consensus trees for both K17 and POL markers (Fig. 3).

T36 was designated the reference strain of the T36 group because of its significance as the first CTV genome fully sequenced (14). B183, B358, and B359 are isolates of the T36 strain based on phylogeny. The B83 isolate is a separate strain within the T36 group because of its terminal position on a separate branch in the POL tree. Isolate B33 also is classified as a separate strain due to incongruent placement within the two trees.

Within the VT Group, T30 is designated the representative strain for T30 genotypes. On the basis of consistent phylogeny, B213, B348, B271, and B270-1 are isolates of the T30 strain.

The K17 marker differentiated isolates designated as T3 or VT genotypes, and phylogenetic analysis of T3 and VT K17 sequences supported segregation of isolates by this marker. Since
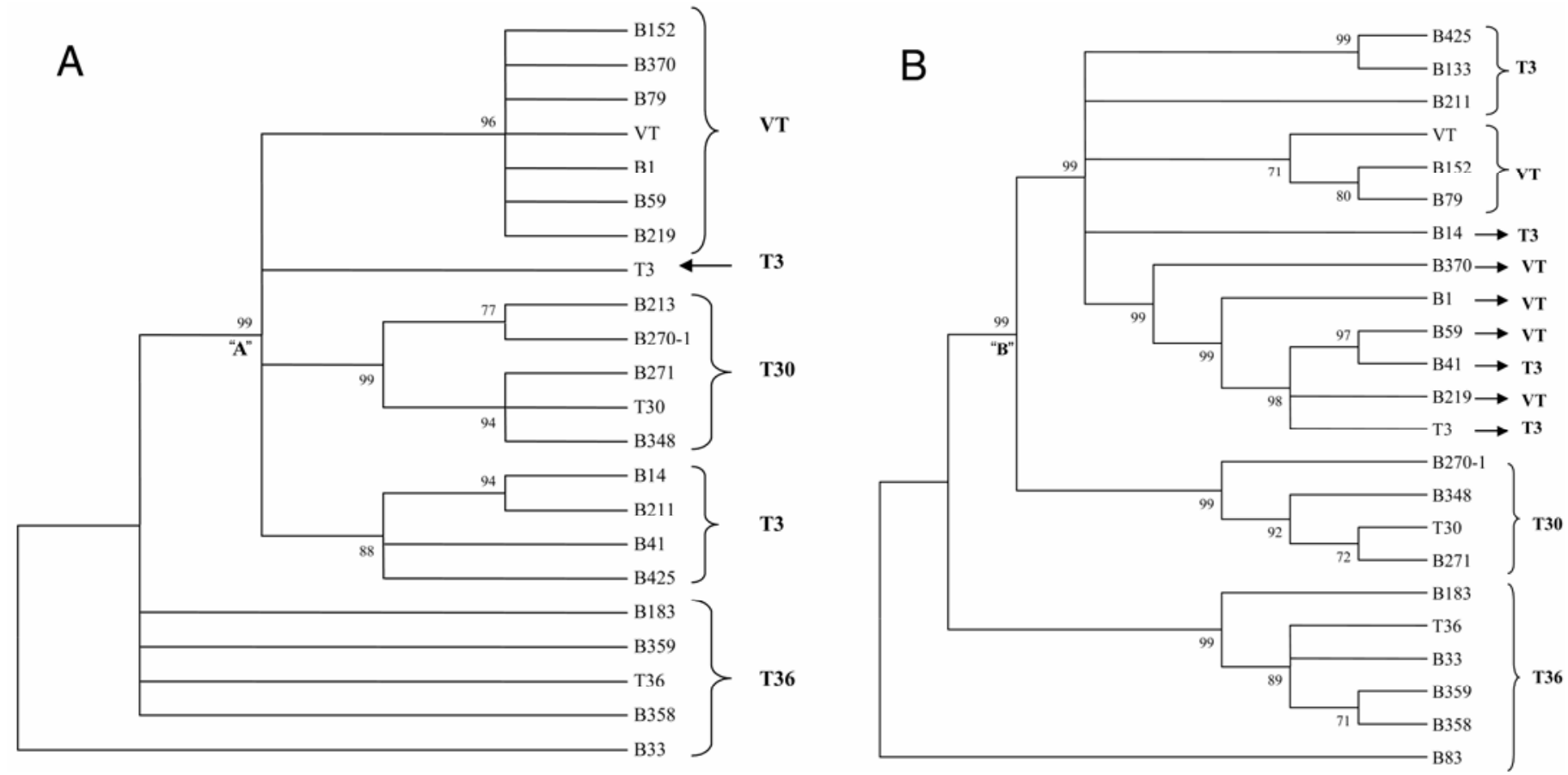

Fig. 2. Phylogenetic relationships among Citrus tristeza virus isolates based on marker sequences. Presented are maximum parsimony consensus trees of A, the K17 marker or B, the POL marker derived by using 1,000 bootstrap replicates. Only branch points with $70 \%$ or greater support are shown. Brackets to the right of the branch termini indicate the assigned genotype using marker profiles. A, The position of the T3 isolate in the K17 tree is indicated by an arrow. B, For the POL marker, genotype assignments based on marker analysis of isolates B14, B370, B1, B59, B41, B219, and T3 are in boldface indicated by arrows. A, Separation of the T36 genotype using marker K17 is denoted at the node labeled "A". B, Separation of the T3 and VT genotypes using marker POL is denoted at the node labeled "B".

\section{VT Group}

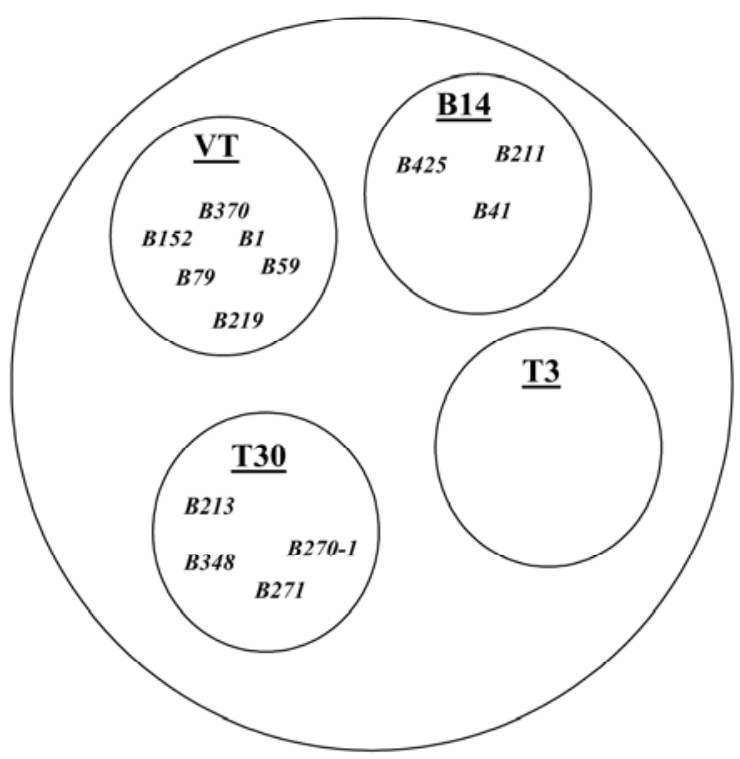

T36 Group

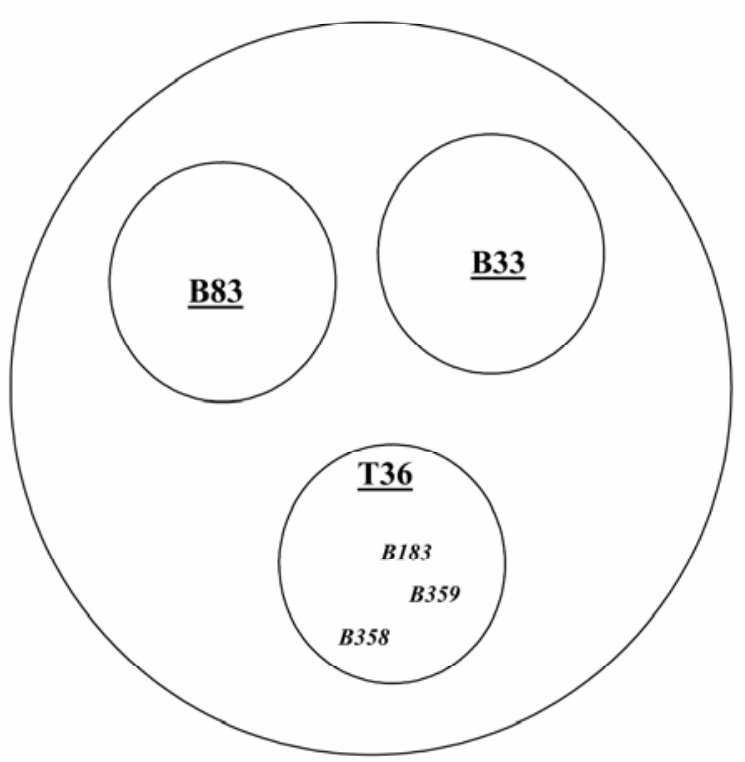

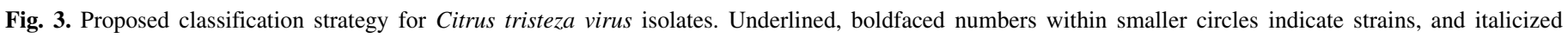
numbers in the same circle indicate isolates of that strain. 
T3 segregated from the other isolates in the K17 tree, it is designated as a distinct strain. B14 is given strain status because of the historical significance of the Capao Bonito area in Brazil from which it was obtained (19). B211, B425, and B41, which clustered with B14, are isolates of the B14 strain. VT was given status as a strain with B1, B59, B79, B152, B219, and B370 defined as isolates of the VT strain.

In this proposed classification scheme, marker analysis would place an isolate in either of the larger groups, while sequence data would determine status as a strain or isolate. CTV isolates which did not yield a recognized marker pattern are not currently encompassed by this classification scheme.

\section{DISCUSSION}

We proposed that isolates of CTV could be grouped together and assigned a specific genotype based on shared patterns of genetic markers $(10,12)$. In this study, we demonstrated phylogenetic support for the assignment of the T30 and T36 genotypes using marker patterns. Among isolates assigned the T30 genotype, there was minimal nucleotide sequence variability among marker sequences and there was phylogenetic agreement for both the K17 and POL markers. In contrast, variability in nucleotide sequence identity of markers was greater among isolates designated as genotype T36, with isolate B83 separated from other members of this group on the basis of maximum parsimony analysis of the POL marker. Also, there was phylogenetic incongruity among the K17 and POL markers for isolate B33. Our results are consistent with data from Rubio et al. (25), who analyzed genome regions of B33 (designated as T308) approximately one $\mathrm{kb} \mathrm{3'}$ and $5^{\prime}$ of the position of the T36K17 marker. Both studies suggest that the B33 genome may have a history of recombination.

With the noticeable exception of the T3 isolate itself, phylogenetic analysis of the K17 marker sequences supported assignment of the T3 and VT genotypes on the basis of marker profiles. The surprising placement of $\mathrm{T} 3$ on a separate branch suggests the T3K17 primers are amplifying two distinct but related groups of sequence. Isolates assigned a T3 or VT genotype shared the VTPOL marker, but phylogenetic analysis of VTPOL sequences did not support assignment of genotype on the basis of this marker alone, and the range of nucleotide sequence identities suggested that the VTPOL primers amplified different sequences. The VTPOL primers amplify part of the P33 ORF, a gene unique to CTV and which is not involved in viral RNA replication (26). Lack of corroboration between assignment of a T3 or VT genotype by phylogenetic analysis of the VTPOL marker and by marker profiles should not detract from the use of the marker system. Since analysis of K17 markers provided phylogenetic support for the current grouping of isolates, and since this marker differentiates T3 and VT profiles, marker analysis is still a useful approach.

Recombinant genomes may constitute a portion of isolates with nonstandard marker profiles or which yielded no markers. The presence of defective RNAs (16) and signatures of recombination in nucleotide sequences (25) suggest recombination has played a role in the evolution of CTV. Yang et al. (33) concluded that isolate SY568 was a mixture of strains, whereas Vives et al. (32) concluded that SY568 was a recombinant virus derived from a genome nearly identical to strain T30 and another distinct CTV genome. Marker analysis of SY568 (isolate B6 in the BARC collection) indicated that SY568 was a mixed infection of a T30 and a VT genotype (data not presented), a conclusion similar to that of Yang et al. (33). It is possible that both conclusions are correct, with both parent sequences and the recombinant sequence existing in the same plant as suggested by Vives et al. (32).

Albiach-Marti et al. (1), remarked on the $\sim 99 \%$ nt sequence identity between the genomes of the Florida isolate T30 (the same as in this study) and the Spanish isolate T385. Both isolates dis- played similar symptom phenotypes and were isolated from similar hosts but were geographically and temporally separated. They concluded there was a high degree of evolutionary stasis in some populations of CTV, even though their temporal separation might have occurred several hundred years in the past. Our data supports the conclusion of stasis for the T30 genotype of CTV. However, data for members of the T3, VT, and T36 genotypes suggest that other CTV populations evolved under different selection pressures.

The observed variability in pathogenicity was substantial, even among isolates which shared the same genotype. There was no clear association of a specific symptom with a specific genotype, although stem pitting in sweet orange was associated mostly with the T3 and VT genotypes. There was, however, a general trend of increased incidence and severity of symptoms associated with the T3 genotype and a decreased incidence and severity of symptoms with the T30 genotype. This general trend was observed by Ayllón et al. (2), who concluded that mild to moderate symptoms were associated with the T30 genotype and more severe stem pitting symptoms in sweet orange or grapefruit with the VT genotype.

CTV isolates may express symptoms in some hosts but not others, suggesting that introduction of CTV into a new region could go unnoticed until transmission to a symptomatic host. Stem pitting in sweet orange trees was first observed in Brazil in 1965. Anecdotal information suggested infected citrus material imported from Japan or southeastern Asia, where stem pitting in sweet orange was prevalent, was the source of CTV causing what was then a new disease (24). Isolate B14 was isolated from a stem-pitted sweet orange tree in Brazil. The phylogenetic position of the T3K17 marker places B14 with isolates from Taiwan (B211 and B41), suggesting an Asian origin for B14 and the T3 genotype.

The independent occurrence of stem pitting in grapefruit and sweet orange suggests separate genetic determinants for these syndromes. Similarly, the induction of the stunting and chlorosis in sweet orange grafted on sour orange by isolates that fail to induce seedling yellows in sour orange suggests that development of the stunting and chlorosis syndrome involves more than a single mechanism. Failure to observe discernable stunting and chlorosis in plants inoculated with isolates collected from some declining trees in the field also indicates that the use of glasshouse tests may not reflect all phloem necrosis effects.

The classification scheme presented here was designed to provide a basis for assessing the relatedness of CTV isolates and suggests more structured definitions of "strain" and "isolate", which currently are used interchangeably. The variability in pathogenicity precluded use of symptom data in the scheme, since for most phenotypes there was no consistent association of specific symptoms with a specific genotype. Although markers can identify T30 and related genotypes with confidence, markers for T3, VT, and T36 genotypes are clearly sampling a larger population that requires nucleotide sequence data to resolve relationships. Also, the current scheme does not consider those isolates which provided confusing or no results from the marker analysis, so sequence data from these is needed if the scheme is to be comprehensive.

Due to small sample sizes for some citrus-producing regions, the CTV collection was geographically biased. Areas such as China, which is part of the proposed origin of diversity of citrus, (28) might be expected to yield a higher proportion of accessions with multiple genotypes, considering the longevity of trees in the field and considering that all four standard genotypes were found in Chinese accessions. However, since the majority of isolates studied came from other established collections or selected surveys, it is reasonable to assume that the collection may not reflect the overall distribution and incidence of CTV genotypes. Differences in the incidence of a particular CTV genotype could depend upon which genotypes are initially introduced and spread in a locality (11). Unbiased surveys are needed to accurately assess CTV biogeography. 
Our intended goal in developing marker analysis protocols was to have a rapid, technically simple method of classifying CTV isolates on the basis of a set of characterized standards. The advantages to this approach are the relatively simple methodology, the use of a set of standard sequences for comparison, and the knowledge that marker patterns have phylogenetic relevance. Problems remain to be resolved, such as generating sequence data for isolates recalcitrant to analysis by the current primer pairs, the need to resolve relationships between isolates that share similar marker patterns, and the need to assess symptoms associated with isolates not assigned a standard genotype. Solutions to these issues are relatively straightforward, however, and should provide additional tools to aid in the dissection of what has been rightfully called a "complex of viruses" (18).

\section{LITERATURE CITED}

1. Albiach-Marti, M. R., Mawassi, M., Gowda, S., Satyanarayana, T., Hilf, M. E., Shanker, S., Almira, E. C., Vives, M. C., López, J., Guerri, R., Flores, R., Moreno, P. M., Garnsey, S. M., and Dawson, W. O. 2000. Sequences of Citrus tristeza virus separated in time and space are essentially identical. J. Virol. 74:6856-6865.

2. Ayllón, M. A., López, C., Navas-Castillo, J., Garnsey, S. M., Guerri, J., Flores, R., and Moreno, P. 2001. Polymorphism of the $5^{\prime}$ terminal region of Citrus tristeza virus (CTV) RNA: Incidence of three sequence types in isolates of different origin and pathogenicity. Arch. Virol. 146: 27-40.

3. Cox, J. E., Fraser, L. J., and Broadbent, P. 1976. Stem pitting of grapefruit: Field protection by the use of mild strains, an evaluation of trials in two climatic districts. Pages 68-70 in: Proc. Conf. Int. Organ. Citrus Virol. 7th. IOCV, Riverside, CA.

4. da Graça, J. V., Marais, L. J, von Broembsen, L. A. 1984. Severe tristeza stem pitting decline of young grapefruit in South Africa. Pages 62-65 in: Proc. Conf. Int. Organ. Citrus Virol. 9th. IOCV, Riverside, CA.

5. Garnsey, S. M., Civerolo, E. L., Gumpf, D. J., Yokomi, R. K., and Lee, R. F. 1991. Development of a worldwide collection of citrus tristeza virus isolates. Pages 113-120 in: Proc. Conf. Int. Organ Citrus Virol. 11th. IOCV, Riverside, CA.

6. Garnsey, S. M., Gonsalves, D., and Purcifull, D. E. 1978. Rapid diagnosis of citrus tristeza virus infections by sodium dodecyl sulfate-immunodiffusion procedures. Phytopathology 68:88-95.

7. Garnsey, S. M., Gumpf, D. J., Roistacher, C. N., Civerolo, E. L., Lee, R. F., Yokomi, R. K., and Bar-Joseph, M. 1987. Toward a standardized evaluation of the biological properties of citrus tristeza virus. Phytophylactica 19:151-157.

8. Gonsalves, D., Purcifull, D. E., and Garnsey, S. M. 1978. Purification and serology of citrus tristeza virus. Phytopathology 68:553-559.

9. Gumpf, D. J., Zheng, G. Y., Moreno, P. M., and Diaz, J. M. 1987. Production and evaluation of specific monoclonal antibodies to citrus tristeza virus strains. Phytophylactica 19:159-161.

10. Hilf, M. E., and Garnsey, S. M. 2000. Characterization and classification of citrus tristeza virus isolates by amplification of multiple molecular markers. Pages 18-27 in: Proc. Conf. Int. Organ Citrus Virol. 14th. IOCV, Riverside, CA.

11. Hilf, M. E., and Garnsey, S. M. 2002. Citrus tristeza virus in Florida: A synthesis of historical, and contemporary biological, serological and genetic data. Pages 13-20 in: Proc. Conf. Int. Organ. Citrus Virol. 15th. IOCV, Riverside, CA.

12. Hilf, M. E., Karasev, A. V., Albiach-Marti, M. R., W. O. Dawson, and Garnsey, S. M. 1999. Two paths of sequence divergence in the citrus tristeza virus complex. Phytopathology 89:336-342.

13. Hilf, M. E., Karasev, A. V., Pappu, H. R., Gumpf, D. J., Niblett, C. L., and Garnsey, S. M. 1995. Characterization of citrus tristeza virus subgenomic RNAs in infected tissue. Virology 208:576-582.

14. Karasev, A. V., Boyko, V. P., Gowda, S., Nikolaeva, O., Hilf, M. E., Koonin, E. V., Niblett, C. L., Cline, K., Gumpf, D. J., Lee, R. F.,
Lewandowski, D. J., and Dawson, W. O. 1995. Complete sequence of the citrus tristeza virus RNA genome. Virology 208:511-520.

15. López, C., Ayllón, M. A., Navas-Castillo, J., Guerri, J., Moreno, P., and Flores, R. 1998. Molecular variability of the 5'- and 3 '-terminal regions of citrus tristeza virus RNA. Phytopathology 88:685-691.

16. Mawassi, M., Karasev, A. V., Mietkiewska, E., Gafny, R., Lee, R. F., Dawson, W. O., and Bar-Joseph, M. 1995. Defective RNA molecules associated with citrus tristeza virus. Virology 208:383-387.

17. Mawassi, M., Mietkiewska, E., Gofman, R., Yang, G., and Bar-Joseph, M. 1996. Unusual sequence relationships between two isolates of citrus tristeza virus. J. Gen. Virol. 77:2359-2364.

18. McClean, A. P. D. 1974. The tristeza complex. Pages 59-66 in: Proc. Conf. Int. Organ. Citrus Virol. 6th. IOCV, Riverside, CA.

19. Müller, G., Rodriguez, W. O., and Costa, A. S. 1968. A tristeza virus complex severe to sweet orange varieties. Pages 64-71 in: Proc. Conf. Int. Organ. Citrus Virol. 4th. IOCV, Riverside, CA.

20. Niblett, C. L., Genc, H., Cevik, B., Halbert, S., Brown, L., Nolasco, G., Bonacalza, B., Manjunath, K. L., Febres, V. J., Pappu, H. R., and Lee, R. F. 2000. Progress on strain differentiation of Citrus tristeza virus and its application to the epidemiololgy of citrus tristeza disease. Virus Res. 71:97-106.

21. Nikolaeva, O. V., Karasev, A. V., Garnsey, S. M., and Lee, R. F. 1998. Serological differentiation of the citrus tristeza virus isolates causing stem pitting in sweet orange. Plant Dis. 82:1276-1280.

22. Permar, T. A., Garnsey, S. M., Gumpf, D. J., and Lee, R. F. 1990. A monoclonal antibody that discriminates strains of citrus tristeza virus. Phytopathology 80:224-228.

23. Roistacher, C. N., and Moreno, P. 1991. A worldwide threat from destructive isolates of citrus tristeza virus. Pages 7-19 in: Proc. Conf. Int. Organ. Citrus Virol. 11th. IOCV, Riverside, CA.

24. Rosetti, V. 1975. Strains of tristeza in South America, Tristeza Addendum Two. Pages 1-7 in: Description and Illustrations of Virus and Virus-Like Diseases of Citrus. A collection of color slides. J. M. Bové and R. Vogel, eds. Vol. 3. Paris Setco IFAC.

25. Rubio, L., Ayllón, M. A., Kong, P., Fernández, A., Polek, M., Guerri, J., Moreno, P., and Falk, B. 2001. Genetic variation of Citrus tristeza virus isolates from California and Spain: Evidence for mixed infections and recombination. J. Virol. 75:8054-8062.

26. Satyanarayana, T., Gowda, S., Boyko, V., Albiach-Marti, R. M., Mawassi, M., Navas-Castillo, J., Karasev, A. V., Dolja, V., Hilf, M. E., Lewandowski, D. J., Moreno, P., Bar-Joseph, M., Garnsey, S. M., and Dawson, W. O. 1999. An engineered closterovirus RNA replicon and analysis of heterologous terminal sequences for replication. Proc. Natl. Acad. Sci. USA 96:7433-7438.

27. Suastika, C., Natsuake, T., Hirotsugu, T., Kano, T., Ieki, H., and Okuda, S. 2001. Nucleotide sequence of citrus tristeza virus seedling yellows isolate. J. Gen. Plant Pathol. 67:73-77.

28. Swingle, W. T. 1967. "The botany of citrus and its wild relatives". in The Citrus Industry. Vol. 1. W. Reuther, H. J. Webber, and L. D. Batchelor, eds. University of California.

29. Thompson, J. D., Gibson, T. J., Plewniak, F., Jeanmougin, F., and Higgins, D. G. 1997. The ClustalX windows interface: Flexible strategies for multiple sequence alignment aided by quality analysis tools. Nucleic Acids Res. 24:4876-4882.

30. Tsai, M.-C., and Su, H.-J. 1991. Development and characterization of monoclonal antibodies to citrus tristeza virus (CTV) strains in Taiwan. Pages 46-50 in: Proc. Conf. Int. Organ. Citrus Virol. 11th. IOCV, Riverside, CA.

31. Vela, C., Cambra, M., Cortés, E., Moreno, P., Miguet, J. G., Pérez de San Román, C., and Sanz, A. 1986. Production and characterization of monoclonal antibodies specific for citrus tristeza virus and their use for diagnosis. J. Gen. Virol. 67:91-96.

32. Vives, M. C., Rubio, L., López, C., Navas-Castillo, J., Albiach-Marti, M. R., Dawson, W. O., Guerri, J., Flores, R., and Moreno, P. 1999. The complete genome sequence of the major component of a mild citrus tristeza virus isolate. J. Gen. Virol. 80:811-816.

33. Yang, Z.-N., Mathews, D. M., Dodds, J. A., and Mirkov, T. E. 1999. Molecular characterization of an isolate of citrus tristeza virus that causes severe symptoms in sweet orange. Virus Genes 19:131-142. 